\title{
Termos psicopatológicos em bandas e músicas de rock and roll
}

\author{
Psychopathological terms in bands and songs of rock and roll \\ Thaísa Silva Gios', Francisco Lotufo Neto²
}

\section{RESUMO}

Objetivo: Investigar o uso de termos psicopatológicos nos nomes de bandas de rock and roll e em suas músicas. Método: Termos psicopatológicos do glossário do DSM-IV foram digitados em português e inglês na página do YouTube. Bandas e músicas de rock and roll foram identificadas. O mesmo procedimento foi realizado, a título de comparação, com o glossário de termos neurológicos da CID-10. Resultados: Foram encontrados nomes de bandas ou músicas referentes a 62 termos psiquiátricos e a 24 termos neurológicos. Os termos psiquiátricos foram mais frequentes, apresentando diferença estatisticamente significativa. Foram encontradas 60 bandas de rock com nomes inspirados na psiquiatria e na neurologia. Dessas, 44 bandas usavam nomes psiquiátricos e 16 bandas usavam termos neurológicos. Bandas e músicas de rock usam mais nomes psiquiátricos que neurológicos. Predominaram nas músicas nomes relacionados ao uso de substâncias. Ao se compararem nomes de bandas e canções brasileiras e estrangeiras, não se encontrou diferença estatisticamente significativa. Conclusão: Bandas de rock and roll usam com maior frequência termos psicopatológicos em seus nomes e em suas músicas. Bandas brasileiras apresentam resultados semelhantes.

\section{ABSTRACT}

Objective: To investigate the use of psychopathology terms in the names of rock and roll bands and in their songs or musics. Method: Psychopathological terms from the DSM-IV glossary were typed in Portuguese and English on the YouTube page. Bands and music of rock and roll were identified. The same procedure was performed, for comparison, with the glossary of neurological terms of ICD-10. Results: Sixty-two psychiatry and 24 neurology related words were used by rock and roll bands and songs. A frequent use of psychiatric and neurological terms in band names and songs of rock was found. The psychiatric terms were more frequent. Sixty bands used psychiatric and neurology related names (44 bands used psychiatry names and 16 neurology). The names predominant in music were related to substance use. When comparing names and songs of Brazilian and other countries bands no difference was found. Conclusion: Rock and Roll bands use with greater frequency psychopathology and psychiatric terms in their names and musics. Brazilian bands held similar results.

1 Universidade Regional de Blumenau (Furb), Blumenau, SC, Brasil.

2 Universidade de São Paulo (FMUSP), Faculdade de Medicina, Departamento de Psiquiatria. 


\section{INTRODUÇÃO}

Durante o século XX a arte foi analisada pela maioria das teorias psicológicas da época. A psiquiatria e a psicoterapia influenciaram o modernismo, o surrealismo, o expressionismo e o pós-modernismo. A arte daquele que sofre de um transtorno mental, denominada por Dubuffet de arte bruta, foi valorizada com a criação de museus especializados e exposições ${ }^{1-3}$.

Cinema e histórias em quadrinhos frequentemente têm como tema a psicopatologia ${ }^{4,5}$. Principalmente no cinema, o doente é visto de forma estereotipada, ora como homicida cruel, ora como muito inteligente, sedutor e iluminado, ora como narcisista, parasita, egoísta e autocentrado. Por vezes é visto como alguém de espírito livre e rebelde, de certa forma destacado da sociedade por sua tendência crítica e desafiadora ${ }^{6}$. Em geral, é mais bem retratado que o psiquiatra e o psicoterapeuta, comumente vistos como portadores de traços psicopáticos ou pouco inteligentes, necessitados da ajuda do paciente.

A interface da música popular brasileira com a psicopatologia foi estudada por Marques Filho et al.7. Essa relação de formas artísticas com a psicopatologia levou à interrogação se isso também ocorre no rock and roll, estilo musical da preferência de muitos jovens. Estudos recentes demonstram associação entre a preferência musical por jazz e rock e tentativas de suicídio, depressão, delinquência, drogas e disfunção familiar. O rock parece proporcionar maior hostilidade, tristeza, fadiga e tensão nos indivíduos em relação aos demais estilos musicais ${ }^{8-10}$. Por esses motivos, o tema merece ser estudado.

\section{OBJETIVO}

Realizar um estudo transversal investigando o uso de termos neurológicos e psicopatológicos em nomes de grupos musicais e músicas de rock and roll e comparar os achados em bandas brasileiras e estrangeiras.

\section{MATERIAIS E MÉTODOS}

Os instrumentos utilizados foram o site YouTube, o DSM-IV e a Classificação Internacional de Doenças 10a edição (CID10). Todos os 144 termos psiquiátricos do glossário do DSM-IV foram utilizados na pesquisa (páginas 45-57). A título de comparação, todos os 241 termos neurológicos do capítulo VI da CID-10 (G00-G99) foram utilizados também (páginas 382-416).

Os termos psicopatológicos presentes no glossário do DSM-IV foram digitados em português e inglês na página inicial do YouTube. A pesquisa na internet foi realizada entre os dias 23/12/2011 e 4/1/2012. As três primeiras páginas de busca foram então analisadas, buscando a presença de nomes de bandas de rock and roll ou músicas. Foram excluídos epônimos que não tiveram inspiração psiquiátrica ou neurológica. Após encontrar as bandas e músicas, buscou-se a nacionalidade delas no próprio site YouTube.

Para comparação dos dados, foi utilizada a mesma metodologia em relação aos termos neurológicos presentes na CID-10.

Os resultados foram organizados em tabelas e analisados pelo teste $t$ de Fisher. Valor de $p$ menor ou igual a 0,05 foi considerado estatisticamente significante.

\section{RESULTADOS}

Foram encontrados nomes de bandas ou músicas referentes a 62 termos psiquiátricos e a 24 termos neurológicos. Os termos psiquiátricos foram mais frequentes, apresentando diferença estatisticamente significativa ( $p=0,000002)$.

\section{Bandas de rock and roll inspiradas na psicopatologia}

Foram encontradas 60 bandas de rock com nomes inspirados na psiquiatria e na neurologia. Dessas, 44 bandas usavam nomes psiquiátricos e 16 bandas usavam termos neurológicos. Bandas de rock usam mais nomes psiquiátricos que neurológicos $(p=0,00009)$. Onze outras bandas foram excluídas por remeterem a nomes próprios ou não terem significado relacionado às áreas em estudo: Rett Kurs, Nina Becker, Zé Paulo Becker, Thane Thomsen, Ove Thomsen, Isaacs, Gregory Isaacs, The Isaacs, Sindrome de Bar, Kanye West, Aura Dione. Esses nomes são epônimos de algumas síndromes psiquiátricas e neurológicas, mas não tiveram inspiração no rock.

Exemplos de bandas nacionais brasileiras que utilizaram nomes psiquiátricos são: Delirium tremens, Hienas Distímicas, Narcolepsia, Carrossel Delirante, Conduta Destrutiva, Esputo Catatônico, Dirty Alcool, Alcool Club, Grupo Substância, Palhaço Paranoide, Banda Paranoide, Parafilia Horrenda, Mc Insônia, Parassônia, Hipersônica, Dissonia, Cleptomania, Distonia, Sem Abuso.

As bandas internacionais encontradas que usam termos psiquiátricos, com as respectivas nacionalidades, são: Delirium Tremens (Alemanha), Delerium (Canadá), Anorexia Nervosa (França), Dispareunia (Peru), Mal de Parkinson (Argentina), Bipolar (Espanha), Distimic Suicide (Chile), Ciclotímico (México), Gallinero Ciclotimico (Argentina), Hardcore Ciclotimico (México), Ciclo Timia (Irlanda), Borderline Insane (Portugal), Santa Demencia (México), Demencia Mortalis (República Tcheca), Demencia (Argentina), Quartet Doloroso (Estados Unidos), Sex Pistols (Inglaterra) e Parafilia (França). Em relação às bandas Borderline, Facticio, Delirium, Sono e Esquizoide, não foram encontradas pela busca no site YouTube a nacionali- 
dade específica e a descrição da banda, e as músicas eram em idioma estrangeiro.

Foram comparadas as bandas brasileiras e estrangeiras (Tabela 1) e seu uso de nomes psiquiátricos e neurológicos. Não foi encontrada diferença estatisticamente significativa $(p=0,77)$.

Tabela 1. Nomes psiquiátricos e neurológicos em bandas brasileiras e estrangeiras

\begin{tabular}{lcc}
\hline & Bandas brasileiras (N/\%) & Bandas estrangeiras (N/\%) \\
\hline Psiquiatria & $20(45,4 \%)$ & $24(54,5 \%)$ \\
Neurologia & $8(50 \%)$ & $8(50 \%)$ \\
\hline$p=0,77$. & &
\end{tabular}

\section{Músicas de rock and roll inspiradas na psicopatologia}

Foram encontrados 176 nomes de canções utilizando termos neurológicos e psiquiátricos. Desses, 159 músicas utilizaram termos psiquiátricos e 17, neurológicos ( $p=0,00009$ ). Foram excluídos sete outros nomes de músicas por não estarem relacionados às áreas em estudo.

Em relação aos termos psiquiátricos, predominaram nas músicas nomes relacionados ao uso de substâncias como: "Esbórnia e álcool", "Anfetamina mil grau", "Cocaína", "Nicotina", "Que corra la nicotina".

Na tabela 2, observam-se os temas psicopatológicos mais frequentes encontrados. Os nomes das bandas e músicas sugestivos de psicopatologia foram classificados em temas pelos autores segundo seu valor de face.

Tabela 2. Temas psicopatológicos usados nos nomes de grupos de rock e em suas canções

\begin{tabular}{lcc}
\hline & Bandas & Músicas \\
\hline Uso de substâncias & 4 & 38 \\
Psicoses & 3 & 12 \\
Sexualidade & 3 & 9 \\
Transtornos de personalidade & 4 & 12 \\
Transtornos do humor & 7 & 13 \\
Transtornos de ansiedade & 0 & 5 \\
Transtornos somatoformes & 0 & 3 \\
Sono & 6 & 26 \\
Cognição & 8 & 12 \\
Transtornos na infância/adolescência & 2 & 7 \\
Transtornos alimentares & 1 & 1 \\
Outros & 7 & 21 \\
\hline
\end{tabular}

Foram encontradas 75 músicas estrangeiras com termos psiquiátricos: 6 norte-americanas, 3 chilenas, 6 italianas, 4 colombianas, 3 neozelandesas, 5 inglesas, 3 canadenses, 3 finlandesas, 3 australianas, 2 francesas, 2 peruanas, 7 argenti- nas, 5 alemãs, 6 mexicanas, 2 equatorianas, 4 espanholas e 3 panamenhas. As demais 8 bandas encontradas não exibiam nacionalidade específica no site YouTube.

Foram comparados os termos neurológicos e psiquiátricos entre as músicas brasileiras e estrangeiras, conforme a tabela 3. Não foi encontrada diferença estatisticamente significativa, com valor de $p$ de 0,44.

Tabela 3. Nomes psiquiátricos e neurológicos em músicas brasileiras e estrangeiras

\begin{tabular}{lcc}
\hline & Músicas brasileiras (N/\%) & Músicas estrangeiras (N/\%) \\
\hline Psiquiatria & $84(52 \%)$ & $75(47,1 \%)$ \\
Neurologia & $11(64,7 \%)$ & $6(35,2 \%)$ \\
\hline$p=0,44$. &
\end{tabular}

\section{DISCUSSÃO}

O rock and roll, desde a década de 1950, possui fama de ser a música da juventude, da rebeldia, da liberdade e do idealismo. A música popular é vista como uma reflexão e uma inspiração para os movimentos de jovens, modas e estilos de vida"1.

A banda é um projeto comum que une e combina a expressão da personalidade de seus membros. O nome da banda está relacionado aos subgêneros com que dialoga, remetendo às suas características musicais e à visão de mundo. Simboliza as aspirações e ideologias dos músicos. Notam-se atualmente muitos nomes de bandas que remetem a temáticas comuns como: destruição, pessimismo, sarcasmo, zombaria e psicopatologia. Nos videoclipes, nas capas de CD e discos, metáforas e grafias tornam as palavras extraordinárias e ampliam o seu significado.

A prevalência de comorbidades psiquiátricas é marcante entre os músicos do rock, como transtornos de ansiedade, transtornos psicóticos e transtornos relacionados ao uso de substâncias ${ }^{12-14}$.

O uso frequente de termos psiquiátricos por bandas e compositores de rock and roll pode ter diversos significados: assinalar a prevalência elevada desses transtornos na população ou o receio e desconforto que esses sintomas provocam; enfatizar a associação do transtorno mental com protesto ou com liberdade individual, ser diferente ou fora dos padrões ou a busca por uma identidade própria que não se conforma com a tradição.

Segundo Bob Gruen ${ }^{15}$, o punké uma atitude. Uma atitude agressiva que questiona autoridade e tudo o mais. Tem a ver com querer um mundo melhor e ficar furioso por não consegui-lo rapidamente. Punk é fazer as coisas do seu próprio jeito, sem orientação ou preocupação com possíveis críticas. O Punk começou a partir dos excluídos e daqueles que não concordavam com a sociedade convencional, com um culto que se formou nos pequenos bares de Nova York e Londres. O bar inicial de muitas bandas, bar CBGB, era um lugar muito 
liberal, em que a única regra imposta pelo proprietário era que as bandas que lá tocavam tinham que escrever suas próprias canções ${ }^{15}$.

Foram encontradas algumas bandas e músicas usando termos neurológicos. Mesmo essa especialidade tão próxima da psiquiatria não despertou o mesmo interesse. No mundo da cultura e das ciências humanas, a preocupação com a psiquiatria é muito maior, é carregada de ideologia e desperta maior polarização e paixão. É incomum encontrar nomes ligados a outras especialidades médicas como gastroenterologia ou cardiologia, por exemplo.

O fenômeno é também internacional. Em diferentes culturas o uso da psicopatologia está relacionado ao nome de bandas e músicas de rock. Países como México, Peru, Argentina, República Tcheca, Inglaterra, Estados Unidos, Portugal, Irlanda, Canadá, entre outros, apresentam nomes de bandas e músicas com termos psiquiátricos em inglês, conforme resultados do presente estudo. O número absoluto de bandas e músicas brasileiras que usam termos psicopatológicos é semelhante ao do resto do mundo. Isso pode ser explicado pela força e atração da cultura anglo-saxã (língua, produtos, roupas, festas, filmes, televisão) e pelos nossos problemas sociais e grande prevalência de transtornos mentais.

O rock and roll parece manter a visão romântica dos transtornos mentais que foi trazida pela contracultura na década 1970, quando a influência da antipsiquiatria estava no auge. O show de rock é um espetáculo muitas vezes fantasioso em que os artistas expõem sob máscaras e músicas seus ideais e comportam-se como a se libertar das convenções-padrão. A iluminação dramática e os efeitos de fumaça deixam a performance parecer surreal; parecem pertencer à outra dimensão, sem regras ou restrições, somente liberdade. Os membros da banda Kiss, por exemplo, tornaram-se únicos, maquiando-se como monstros, cuspindo fogo e sangue ${ }^{15}$.

Expressar comportamentos e usar nomes de sintomas e transtornos mentais permitiria atos impulsivos e inconsequentes, às vezes amorais, mas também uma catarse coletiva, estados alterados de consciência que aliviam ansiedades, tristeza e angústias. Até mesmo perante a justiça a conduta diante de alguém com transtorno mental é diferente: a incapacidade de entender o caráter ilícito de seus atos permite que o doente mental seja considerado inimputável e tenha julgamento e pena diferenciados. Na visão romântica do rock and roll, suspender a ordem e as regras seria sinônimo de liberdade ou agressão à ordem estabelecida. Tal observação lembra a famosa frase de Raul Seixas, famoso cantor roqueiro, na época da contracultura dos anos 1970: "Faz o que tu queres há de ser tudo da lei".

No presente estudo predominou nas músicas pesquisadas termos relacionados ao uso de substâncias como: álcool, anfetamina, cocaína e nicotina. Foram encontradas 38 músicas relacionadas a esse tema. Dessas, apenas uma defendia o abandono das drogas, enfatizando seus efeitos deletérios.
As demais 37 incentivavam o uso. O impacto que isso pode ter merece ser analisado. As drogas ilícitas por si só remetem à ideia de anarquia, geralmente presente nas músicas de rock. Em 2008, um estudo analisou o conteúdo de 279 músicas populares norte-americanas, constatando que 33,3\% referenciaram o uso de substâncias. Dessas músicas, 66 eram rock e 62 rap e, respectivamente, 14\% e 77\% delas incentivavam o uso. Do total de músicas, 2,9\% referenciaram o tabaco, 23,7\% o álcool, 13,6\% a maconha e 11,5\% drogas inespecífcas. O uso da droga foi associado com festas, sexo, violência e humor. Somente $4 \%$ das músicas expuseram mensagens antiuso de drogas ${ }^{13}$. O mesmo fenômeno é encontrado na música popular brasileira. Segundo resultado de estudo brasileiro de 2004, ao estudar a relação entre substâncias e músicas populares, há predominância de músicas discursando a favor da discriminação da cannabis por seu caráter dito inofensivo e pretensas vantagens de seu uso; uma minoria de músicas enfatiza os riscos de dependência da cannabis, do álcool e da heroína?.

Conhecer rock and roll pode facilitar o estabelecimento de vínculo com adolescentes e jovens aficionados e pode facilitar atividades terapêuticas discutindo letras de músicas. Porém, a apropriação de termos médicos pelo vocabulário popular, como "esquizofrênico", "imbecil" e "cretino", e sua atribuição em casos cotidianos sem nenhum rigor científico, assim como o uso metafórico desses termos com significados depreciativos e insanos, pode contribuir para o estigma que alguns transtornos mentais possuem, dificultando a procura de tratamento para as comorbidades psiquiátricas e segregando parte da sociedade ${ }^{16}$. A visão antipsiquiátrica ou o reducionismo psicológico pode ser prejudicial, pois as pessoas podem ter dificuldade de separar o normal do patológico e buscar ajuda. O incentivo de muitas músicas ao uso de substâncias é outro ponto negativo que separa a Psiquiatria do rock and roll.

\section{CONTRIBUIÇÕES INDIVIDUAIS}

Os dois autores trabalharam ativamente em todas as fases do projeto.

\section{CONFLITOS DE INTERESSE}

Não há.

\section{REFERÊNCIAS}

1. Aguilar N. Imagens do inconsciente. In: Mostra do Redescobrimento. Fundação Bienal de São Paulo: Associação Brasil 500 anos Artes Visuais; 2000.

2. Green J. Psychiatry and the arts: New interfaces. Adv Psych Treat. 2008;14:163-8. 
3. Ferraz MH. Arte e loucura: limites do imprevisível. São Paulo: Lemos; 1999

4. Castilho JM , Castilho SM, Maia MC, Lotufo Neto F. Psicopatologia no cinema brasileiro: um estudo introdutório. Rev Psiq Clín. 2005;3:319-23.

5. Bonomi TA, Lotufo Neto F. Psicopatologia nas histórias em quadrinhos e cartoons. Rev Psiq Clín. 2010;37:291-5.

6. Oliva VHS, Zorzetto Filho D, Lotufo Neto F. 0 retrato da psiquiatria pelos cinemas norte-americano e brasileiro. Rev Psiq Clín. 2010;37:89-95.

7. Marques Filho AB, Cruz EMTN, Souza DRS. A expressão cultural das substâncias: subsídio da música e do discurso populares. Rev USP São Paulo. 2004;63:197-218.

8. Wills $\mathrm{Gl}$. Forty lives in the bebop business: mental health in a group of eminent jazz musicians. Brit J Psichiatry. 2003;9:255-9.

9. McCraty R, Barrios CB, Atkinson M, Tomasino D. The effects of differents types of music on mood, tension, and mental clarity. Altern Ther Health Med. 1998:4:75-84.
10. Martin G, Clarke M. Adolescent suicide: music preference as an indicator of vulnerability. J Am Acad Child Adolesc Psychiatry. 1993;32:530-5.

11. Ashby SL, Rich M. Video killed the radio star: the effects of music videos on adolescent health. Adolesc Med Clin. 2005;16:371-93.

12. De Alencar JT. Estilo e autenticidade em bandas de rock de Florianópolis (SC). Psic Sociedade. 2008;20:208-16.

13. Primack B, Dalton M. Content analysis of tobacco, alcohol, and other drugs in popular music. Arch Pediatr Adolesc Med. 2008;162:169-75.

14. Sartin JS. Contagious rhythm: infectious diseases of 20th century musicians. Clin Med Res. 2010;8:106-13.

15. Gruen B. Rockers: Bob Gruen. São Paulo: Cosac Naify; 2007.

16. Guarniero FB, Bellinghini RH, Gattaz WF. The schizophrenia stigma and mass media: a search for news published by wide circulation media in Brazil. Rev Psiq Clín. 2012:39(3):80-4. 